Cadernos Walter Benjamin 20

\title{
SERÁ QUE PODEMOS DESTRUIR NOSSO DESTINO?
}

Vinícius Nicastro Honesko

\begin{abstract}
RESUMO
O presente ensaio analisa o problema do mito e do destino a partir das conceitualizações de Walter Benjamin. Além disso, pretende mostrar como essas reflexões benjaminianas são tomadas por um leitor que as desenvolve no âmbito da mitologia: Furio Jesi. Em um primeiro momento, o ensaio demonstra como Benjamin pensa as noções de mito e como ele as vincula à dimensão política (tanto no pensamento fascista como no socialdemocrata). Em seguida, aponta para uma possível resposta que Benjamin dá à destinação mítica no âmbito político (por meio da figura do caráter). Na sequência, aborda como essa reflexão benjaminiana é absorvida e desenvolvida por Furio Jesi, sobretudo na compreensão do modelo gnosiológico da máquina mitológica e de suas implicações na dimensão política nas noções de revolta e revolução. Por fim, expõe como Jesi, apontando para os limites de seu próprio modelo, pensa, em moldes benjaminianos, a destruição de sua máquina como uma possibilidade política para além da revolta ou da revolução.
\end{abstract}

Palavras-chave: Destino. Mito. Dimensão política. Máquina mitológica.

\section{CAN WE DESTROY OUR FUTURE?}

\begin{abstract}
The present essay analyses the problem of myth and destiny from the conceptualizations of Walter Benjamin. Moreover, it intents to exhibit how these benjaminian's reflections are taken and developed in the scope of mythology by a reader of Benjamin: Furio Jesi. At first, the essay demonstrates how Benjamin thinks the notions of myth and how he links them to the political dimension (both in fascist and social-democratic thinking). In sequence, it points to a possible answer given by Benjamin to the mythical destination on the political scope (by means of the figure of the character). Then, it addresses how this thought of Benjamin is absorbed and developed by Furio Jesi, especially on his gnoseological model: the mythological machine. It also exhibits how this machine has deep implications in the political dimension, mainly in the revolt and revolution notions. Finally, it exposes how Jesi, pointing to the limits of his own model, thinks, in a benjaminian manner, the destruction of his machine as a political possibility beyond the revolt or the revolution.
\end{abstract}

Keywords: Destiny. Myth. Political dimension. Mythological machine.

Doutor em Literatura pela Universidade Federal de Santa Catarina (UFSC). Atualmente é Professor Adjunto no Departamento de História da Universidade Federal do Paraná (UFPR). Brasileiro, residente em Curitiba-PR. Email: viniciushonesko@gmail.com 
O materialista histórico, ao seguir a estrutura da história, entrega-se, a seu modo, a uma espécie de análise espectral. Do mesmo modo como o físico identifica o ultravioleta no espectro de cores, assim também ele identifica na história uma força messiânica. Aquele que quer saber em que condição se encontra a "humanidade redimida", a que pressupostos está sujeita a entrada nessa condição e quando se poderá contar com ela está a fazer perguntas para as quais não há resposta. É o mesmo que perguntar qual é a cor dos raios ultravioleta.

Walter Benjamin (manuscrito 1099 do arquivo W.B)

Na emissão radiofônica de 31 de janeiro de 1931, na rádio Berliner Rundfunk, Walter Benjamin comenta sobre o Terremoto de Lisboa de $1^{\circ}$ de novembro de 1755. Benjamin fala por 20 minutos e começa justificando seu modo de narrar com uma comparação entre um farmacêutico - que, ao preparar um remédio, pesa grama a grama as substâncias e pozinhos que entram na composição - e ele, Benjamin, que pesa com rigor o que fala dentro dos minutos que tem à disposição. E essa justificativa lhe parece necessária sobretudo no caso específico do terremoto de Lisboa:

\footnotetext{
Direis com certeza: Ora, mas que comparação! Se nos quer contar alguma coisa sobre o terremoto de Lisboa, então comece por dizer como começou. E depois conta o que aconteceu a seguir. - Mas, se eu fizesse as coisas desse modo, duvido que isso vos divertisse. Casas a ruírem umas a seguir às outras, famílias a morrer umas atrás das outras, os terrores do fogo a alastrar e os terrores das águas, a escuridão e os saques e os lamentos dos feridos e dos que procuram os familiares... Ouvir contar isso e apenas isso não agradaria a ninguém, e no entanto são coisas dessas que acontecem e se repetem em qualquer catástrofe natural. (BENJAMIN, 2015, p. 140)
}

Benjamin então passa a tecer comentários sobre a especificidade do terremoto e o que ele representou de fato e no imaginário tanto do século XVIII quanto até 100 anos depois, quando ainda se tinham novos relatos sobre a catástrofe. Além disso, remete-se às repercussões que se ouviram por toda a Europa e também aos folhetos que descreviam, à época do terremoto, os 
terríveis acontecimentos em suas minúcias. Lê, de um desses folhetos, as descrições de um inglês que morava em Lisboa e, por fim, conclui:

Eis o que se passou nesse fatídico dia 1 de Novembro de 1755. A catástrofe que ele trouxe é uma das poucas em relação às quais os homens continuam hoje a ser tão impotentes como há 170 anos. Mas também neste domínio a técnica encontrará meios, nem que seja indirectamente, através das previsões. Por enquanto, ao que parece, os sentidos apurados de alguns animais são ainda superiores aos nossos melhores instrumentos. Em especial os cães, que dias antes dos terramotos parecem mostrar já um desassossego tão evidente que em algumas regiões eles são usados nas estações sismológicas. (BENJAMIN, 2015, p. 144)

Antes, porém, desse final em que, talvez em tom paradoxalmente irônico - importante seria lembrar das palavras sobre o positivismo no texto sobre Eduard Fuchs ${ }^{1}$-, a técnica é comparada à intuição natural dos cães, e ainda permanece em déficit em relação a esta, Benjamin faz um pequeno excurso sobre a formação dos terremotos a partir das concepções da ciência de seu tempo. Para tanto, recorre, de início, às anotações que Kant faz sobre o terremoto e de como estas representaram o início daquilo que será chamado de sismologia. É interessante voltar a essas notas kantianas para perceber como e de que maneira já nestas a impotência dos humanos diante da natureza, sobre a qual fala Benjamin ao final de sua exposição sobre o terremoto de Lisboa, aparece. Na primeira das notas kantianas, publicada nos dias 24 e 31 de janeiro de 1756, no noticiário semanal de Königsberg, o filósofo reflete sobre as causas dos sismos e elabora uma série de hipóteses sobre como eles acontecem. Todavia, ainda nas preliminares das hipóteses, é uma inquietação de Kant que nos chama a atenção:

Habitamos tranquilamente um solo cujas bases são sacudidas de vez em quando. Construímos, sem nos preocupar, sobre abóbodas cujos pilares por vezes vacilam e ameaçam desmoronar. Descuidados da

\footnotetext{
${ }^{1}$ Cf.: BENJAMIN, Walter. Eduard Fuchs, colecionador e historiador. In.: BENJAMIN, Walter. O Anjo da História. Belo Horizonte: Autêntica, 2013. Trad.: João Barrento. p. 135. "As questões que a humanidade coloca à natureza são codeterminadas pelo estágio da sua produção. É esse o ponto em que o positivismo fracassa, porque, na evolução da técnica, só foi capaz de reconhecer os progressos da técnica, não os retrocessos da sociedade. Mas não se apercebeu de que essa evolução foi decisivamente determinada pelo capitalismo. E também aos positivistas entre os teóricos socialdemocratas escapou o fato de que tal evolução tornou cada vez mais precário o ato, que se revelava cada vez mais urgente, de uma futura tomada de posse dessa técnica pelo proletariado. E ignoram o lado destrutivo desses desenvolvimentos porque se tinham alheado do lado destrutivo da dialética."
}

Doutor em Literatura pela Universidade Federal de Santa Catarina (UFSC). Atualmente é Professor Adjunto no Departamento de História da Universidade Federal do Paraná (UFPR). Brasileiro, residente em Curitiba-PR. Email: viniciushonesko@gmail.com 


\begin{abstract}
fatalidade, que talvez não se encontra tão distante de nós, cedemos o lugar do medo à compaixão quando nos damos conta da desolação que causa em nossos vizinhos a catástrofe oculta abaixo de nossos pés. Sem dúvidas, constitui um favor da Providência não sermos perturbados pelo medo de semelhantes fatalidades, contra as quais toda possível preocupação não pode fazer absolutamente nada para impedi-las, e, em tais casos, nosso sofrimento real tampouco pode contribuir para aumentar o medo diante do que consideramos apenas como possível. (HERNANDES MARCOS, 2005, p. 218)
\end{abstract}

A percepção da submissão às forças incontroláveis de uma natureza que pode ser devastadora é amenizada por um favor que nos concede o governo divino do mundo - a Providência. Ainda assim, Kant, como Ihe seria imperioso, pensa que um saber profundo sobre a natureza é fundamental para que, no curso da história humana, seja possível afrontar essas catástrofes com a medida do conhecimento, o qual, mesmo diante das forças da natureza, não seria um esforço temerário e inútil. Entretanto, Kant se pergunta sobre o porquê da insistência em reconstruir Lisboa no mesmo lugar onde, como mostra a experiência e o saber que se pode avançar a partir de então, um novo terremoto poderia acontecer. Uma resposta para isso, sugere o filósofo, está no fato de que a maioria dos homens, diante desses casos, posiciona-se de modo diverso a esse seu argumento. O medo Ihes privaria a reflexão e, com isso, eles "creem perceber em catástrofes tão gerais um tipo de mal diferente daquele frente ao qual cabe tomar precauções, e, assim, pretendem atenuar a dureza do destino mediante uma submissão cega, por meio da qual a este se entregam incondicionalmente." (HERNANDES MARCOS, 2005, 219, grifo nosso)

Precaver-se por meio de uma decisão racional ou atenuar as agruras do destino inexorável por meio de uma submissão incondicional às forças que nos escapam totalmente: essa parece ser a encruzilhada entre um caminho à emancipação - que inclui o afrontamento racional das forças natureza para, no mínimo, poder aventar hipóteses que nos livrariam de catástrofes - ou um caminho à submissão que, diante dessas forças recônditas, apenas procura meios de apaziguar as consciências com justificativas míticas que recobrem as verdadeiras causas (a origem) dessas forças. Kant então aventa um primeiro argumento sobre as origens dos terremotos: a questão das grutas que se formam sob a crosta terrestre, onde gases incandescentes do centro da Terra

Doutor em Literatura pela Universidade Federal de Santa Catarina (UFSC). Atualmente é Professor Adjunto no Departamento de História da Universidade Federal do Paraná (UFPR). Brasileiro, residente em Curitiba-PR. Email: viniciushonesko@gmail.com 
impõem uma pressão que acaba por gerar o terremoto (algo que estará em sua hipótese nebular). Entretanto, mais do que esmiuçar essa problemática, é importante frisar um trecho do argumento de Kant que inquire sobre as causas. Diante do necessário recuo através das causas, Kant parece esbarrar em um limite.

\begin{abstract}
Se tivesse que dizer algo inteligível acerca das causas que na formação da Terra deram origem a essas grutas, deveria voltar na história da Terra até o caos. Só que tais explicações têm demasiadamente a aparência de ficções quando alguém não pode expô-las no marco íntegro dos fundamentos que a elas outorgam credibilidade. (HERNANDES MARCOS, 2005, p. 218)
\end{abstract}

Seria interessante seguir uma argumentação sobre questões epistêmicas e gnosiológicas a respeito dessa necessidade de fundamentos que outorguem credibilidade às explicações sobre as origens dos terremotos e, no limite, da Terra. Todavia, não é diretamente este o problema que será comentado neste ensaio. Antes, é a partir de duas questões levantadas por Kant e que são, de uma maneira muito particular, absorvidas por Benjamin que os argumentos aqui serão desenvolvidos: a submissão ou emancipação em relação ao destino e a aparência de ficção das explicações das origens.

Em meados de 1919, ainda sob os influxos da revolta espartaquista do ano anterior, Benjamin redige o ensaio Destino e Caráter, no qual distingue ambos os termos do seguinte modo: o destino estaria atrelado à dimensão da natureza (da natureza mítica, dirá no ensaio As afinidades eletivas de Goethe², que nos liga a uma espécie de culpa) enquanto o caráter seria ligado a uma dimensão moral (dimensão esta, porém, complexa e que, nesse jovem Benjamin, estaria ligada a certa leitura de Kant ${ }^{3}$; todavia, ainda que essa leitura esteja em certo sentido correta, não seria apenas esse o fator decisivo no conceito de caráter). Imprescindível, no entanto, é perceber que o destino aí

\footnotetext{
2 Cf.: BENJAMIN, Walter. As afinidades eletivas de Goethe. In.: BENJAMIN, Walter. Ensaios reunidos: escritos sobre Goethe. São Paulo: 34/Duas Cidades, 2009. Trad.: Mônica Krauz Bornebusch, Irene Aron e Sidney Camargo. p. 45. "Esse estudo baseia-se em um duplo sentido, ora ingênuo, ora bem mais ponderado, referente ao conceito de natureza. Porque em Goethe tal conceito designa tanto a esfera dos fenômenos passíveis de percepção como a dos arquétipos passíveis de contemplação."

3 Cf.: GAGNEBIN, Jeanne Marie. Mito e culpa nos escritos de juventude de Walter Benjamin. In.: GAGNEBIN, Jeanne Marie. Limiar, Aura e Rememoração. Ensaios sobre Walter Benjamin. São Paulo: 34, 2014.
}

Doutor em Literatura pela Universidade Federal de Santa Catarina (UFSC). Atualmente é Professor Adjunto no Departamento de História da Universidade Federal do Paraná (UFPR). Brasileiro, residente em Curitiba-PR. Email: viniciushonesko@gmail.com 
está ligado a uma percepção da natureza enquanto um mito, algo fundamental para a compreensão de uma dimensão da culpa. Em um trecho central do texto, Benjamin diz:

O destino se mostra portanto quando se considera a vida de um condenado, no fundo, uma vida que primeiro foi condenada e por isso tornou-se culpada (...). Destino é o nexo de culpa do vivente. Este nexo corresponde à constituição natural do vivente, a esta aparência ainda não totalmente dissolvida, da qual o homem está tão afastado que ele jamais mergulha nela inteiramente, mas sob o domínio da qual ele não pode senão permanecer invisível no que ele tem de melhor. Assim, no fundo, o homem não é aquele que possui um destino; o sujeito do destino é indeterminável. O juiz pode entrever o destino onde quiser; cada vez que pune, ele deve, ao mesmo tempo, às cegas, ditar um destino - destino no qual o homem jamais é atingido, mas apenas a mera vida nele que, em virtude da aparência, participa da culpa natural e da infelicidade. (BENJAMIN, 2011, p. 94)

Essa complexa compreensão de um destino que é um mito que, por sua vez, é o que liga nossa vida natural a uma culpabilidade também natural, é desenvolvida por Benjamin no ensaio de 1922, As afinidades eletivas de Goethe, quando diz que o "destino é a correlação de culpa do vivente" (BENJAMIN, 2009, 31) e, afirmando a submissão do humano ao destino, completa: "o ser humano não escapa ao infortúnio que a culpa chama sobre ele. Assim como cada movimento dentro dele provocará culpa, cada um de seus atos haverá de trazer-Ihe a desgraça" (BENJAMIN, 2009, p. 32). Lembranos Jeanne Marie Gagnebin que essa oposição entre destino e caráter está fincada numa anterior, entre mito e história, que é ligada muito mais à tradição judaica do que à filosofia grega. ${ }^{4}$ Todavia, esse não é o único ponto. É decisivo apontar par o fato de que, em um espectro político antagônico, por assim dizer, ao de Benjamin, a discussão sobre o mito ganhava outras feições na Alemanha dos anos 20: Carl Bernoulli, Ludwig Klages ${ }^{5}$ e Alfred Baeumler são aqueles que

\footnotetext{
${ }^{4}$ Cf.: GAGNEBIN, Jeanne Marie. Apresentação. In..: BENJAMIN, Walter. Escritos sobre Mito e Linguagem. São Paulo: 34/Duas Cidades, 2011. Org.: Jeanne Marie Gagnebin. Trad.: Susana Kampf Lages e Ernani Chaves. p. 9.

5 É importante lembrar que Benjamin conhece Klages desde a época do movimento estudantil, conforme atesta a carta a Ernst Shoen, de 22/23 de junho de 1914. Mas é em carta a Scholem de 14/01/1926 em que afirma que um confronto com Klages e Bachofen será inevitável. Cf.: ADORNO, Theodor; SCHOLEM, Gershom (org.). The correspondence of Walter Benjamin. 1910-1940. Chicago: The University of Chicago Press, 1994. Translated by Manfred R. Jacobson and Evelyn M. Jacobson. p. 69; 288. Importante também frisar o espanto manifestado por Benjamin - em carta escrita, durante sua viagem pelo mar do norte, para Scholem, em 15/08/1930 - diante do livro Der Geist als Widersacher der Seele, de Klages. Cf.: Idem. p. 366. "I produced a cycle, 'Nordische See', which you will, of course, get to see very

Doutor em Literatura pela Universidade Federal de Santa Catarina (UFSC). Atualmente é

Professor Adjunto no Departamento de História da Universidade Federal do Paraná (UFPR). Brasileiro, residente em Curitiba-PR. Email: viniciushonesko@gmail.com
} 


\title{
protagonizam a chamada Bachofen Renaissance e apresentam um interesse
} pelo mito como uma verdade profunda (algo que, ademais, encontrará em

\author{
certos traços da filosofia de Heidegger, e em vários de seus leitores, um
}

soon. I translated Jouhandeau while on board ship. And then for the entire trip I devoted myself to the most recent mythologicis. You probably already have one in front of you, [Erich] Unger's Wirklichkeit, Mythos) Erkenntnis. On the other hand, I do not know if Klages's major work, Der Geist als Widersacher der Seele, is already being discussed in Jerusalem. As for me, I took a rather perfunctory look at the first volume; to study it thoroughly would take many weeks. It is without a doubt a great philosophical work, regardless of the context in which the author may be and remain suspect. It would be quite futile for me to attempt to give you some indication here of what it is about. I also have not yet taken any 'position' on what is in the book. I would never have imagined that the kind of clumsy metaphysical dualism that forms the basis of Klages's book could ever be conjoined with really new and wide-ranging conceptions. Since taking up residence here, I have spent time on Unger's book and have now managed to choke down twothirds of it. I am thoroughly and completely disappointed: I have seldom come across so much clumsiness combined with so much dryness in a philosophical study." Além disso, é interessantíssimo o apontamento de Barbara Chitussi sobre a citação indireta (e quase literal) que Benjamin faz de Klages na conceituação de aura em $A$ obra de arte na era da reprodutibilidade técnica. Cf.: CHITUSSI, Barbara. Aura e imagem onírica em Walter Benjamin. Texto inédito cuja tradução, de Vinícius Honesko, está no prelo pela editora UFMG, em livro organizado por Márcio Seligmann-Silva e Georg Otte: "Gostaria agora de analisar dois aspectos da questão: o primeiro, diz respeito à formulação do conceito de aura no texto de 1936, que corresponde, a meu ver, a uma reelaboração da noção klagesiana de Ferne (distância). O segundo, diz respeito à tentativa realizada por Benjamin, tanto por meio do escrito de 1936 como por alguns escritos sucessivos, de definir uma teoria estética e, ao mesmo tempo, política, capaz de turbar o árido dualismo klagesiano.

Lembremos da definição de aura apresentada no ensaio sobre a reprodutibilidade técnica. Trata-se de uma teia singular, composta de elementos espaciais e temporais: a aparição única de uma coisa distante, por mais perto que ela esteja. Observar, em repouso, numa tarde de verão, uma cadeia de montanhas no horizonte, ou um galho, que projeta sua sombra sobre nós, significa respirar a aura dessas montanhas, desse galho.

A semelhança dessa definição com algumas passagens de Klages é estupefaciente. Penso, em primeiro lugar, em Vom Wesen des Bewusstseins, no qual Klages descreve a presença das imagens originárias nas coisas:

'Se no átimo fecundo o homem 'psíquico', em vez de perceber apenas o carvalho (...), é capaz de contemplar a imagem originária no mesmo fato que para nós significa apenas essa árvore com tais e quais propriedades, pois a ele apareceu uma alma demoníaca (...) que adverte a emoção fluida que vem de cima sussurrando misteriosamente (...), o homem pneumático, cuja alma tornou-se cega pela aureola, percebe sempre aquela determinada árvore (...) como cortada fora do Panteão da vida.'

Vejam bem que se trata do mesmo exemplo escolhido por Benjamin - o da árvore e do olhar que segue o galho - e da mesma palavra-chave: aura.

Ainda que Benjamin torne tal imagem histórica - a aura não é eterna como para Klages, mas típica da percepção humana na época da arte tradicional -, trata-se da mesma experiência. A semelhança é todavia ainda mais evidente pensando-se na noção central da obra mais lida de Klages, Vom kosmogonischen Eros (1922): a noção de Ferne. Afirmando que a aura é a aparição única de "uma coisa distante", Benjamin, com efeito, cita de maneira implícita Klages: 'O olhar de quem está imerso na observação, mesmo se fosse também de um objeto próximo, é tomado, de modo privado de escopos, pela imagem do objeto (...) o modo de observação decide se ele tem a característica do próximo ou do distante (...) a proximidade tem o caráter da coisa (Dinge), o afastamento aquele da imagem'. E por fim: 'Próximo e distante são os polos do espaço e do tempo (...) o afastamento temporal aparece no afastamento espacial (...) 0 tempo é a alma do espaço'. Aqui é evidente que a trama de espaço e tempo do texto de Benjamin é apenas uma reelaboração da expressão de Klages 'o tempo é a alma do espaço'."

Doutor em Literatura pela Universidade Federal de Santa Catarina (UFSC). Atualmente é

Professor Adjunto no Departamento de História da Universidade Federal do Paraná (UFPR). Brasileiro, residente em Curitiba-PR. Email: viniciushonesko@gmail.com 
desenvolvimento). Que Benjamin venha a escrever sobre Bachofen apenas em 1934 não significa, como nos lembra João Barrento, ${ }^{6}$ que ele não tenha tido contado com Bachofen anteriormente, ainda no final da década de 10. Assim, é importante frisar que sua concepção de mito já estaria, também no início dos anos 20, marcada por uma contra-face a estes que, de certa maneira, estarão direta ou indiretamente ligados à construção do mito de uma comunidade plena - que, radicalizado naqueles anos na Alemanha, chegou na construção do mito nazista. E talvez seja interessante, como modo de confrontação in negativo, apontar uma definição de mito que advém de Luigi Pareyson, um dos leitores de Heidegger que, aqui, pode ser colocado numa dimensão antagônica - mais próxima à de Klages, por exemplo - à de Benjamin. Diz ele:

\begin{abstract}
por "mito", como dizia, compreendo o nível profundo da relação ontológica, a interpretação originária da verdade, o contato com o inobjetivável, o qual não deve ser considerado como contraposto à "realidade", porque o mito é ele mesmo uma experiência existencial da realidade; não contraposto à "história", pois o mito é uma narrativa, narração, uma história das épocas da eternidade, das épocas da história humana, da história temporal; nem contraposto à "verdade", pois ele é a verdade enquanto existencialmente interpretada e possuída; não contraposto à "razão", pois ele contém um pensamento, mesmo que seja um pensamento originário, ou, digamos, um pensamento não conceitual, mas real, que se exprime numa consciência real, numa consciência muda; nem, muito menos, como contraposto à "revelação", porque ele é não apenas invenção ou expressão, não somente função fabuladora ou mitopoiética, mas é revelador. (PAREYSON, 2017, p. 42)
\end{abstract}

Ora, mito aqui (com toda a complexidade de uma hermenêutica do mito que Pareyson irá desenvolver ao longo de seu projeto Ontologia da Liberdade), pode ser lido no polo negativo à postulação benjaminiana, ou seja, para Pareyson, o mito seria aquilo que revelaria aos humanos o acesso a uma verdade intangível; não um destino preso à culpa que condena o homem à infelicidade, mas justamente o contrário, aquilo que poderia liberar o homem da culpa que ele mesmo se impõe, que poderia devolver-lhe a graça. Em chave reversa, essa imagem do mito pode iluminar a compreensão benjaminiana que diz que o mito nada nos revela, mas, pelo contrário, como destino, ele nos

6 Cf.: BARRENTO, João. Comentários. In.: BENJAMIN, Walter. O anjo da história. Belo Horizonte: Autêntica, 2013. Trad.: João Barrento. p. 217-218.

Doutor em Literatura pela Universidade Federal de Santa Catarina (UFSC). Atualmente é Professor Adjunto no Departamento de História da Universidade Federal do Paraná (UFPR). Brasileiro, residente em Curitiba-PR. Email: viniciushonesko@gmail.com 
cega $^{7}$ e nos impulsiona à desgraça, e para nós é uma imposição da condição natural, de nossa mera vida de ser vivente. Além disso, essa noção do mito como revelação e não contraposto à história também pode apontar para uma percepção de Benjamin diante do fascismo (fascismo que, naqueles anos, pensava, justamente, uma possibilidade de um mito originário como revelador de uma verdade). Aliás, já no ensaio As afinidades eletivas de Goethe essa irrupção do mito na história ${ }^{8}$ parece se dar por meio de uma dimensão de idolatria da natureza - "uma panarquia amorfa da vida natural que constitui o domínio do mito" (GAGNEBIN, 2014, 50) - por parte de Goethe, de modo que, por exemplo, a retomada de Bachofen pelo espectro político fascista pode apontar para essa compreensão do mito que advém como revelação profunda de uma verdade, no caso, para o povo alemão.

Para Benjamin, por outro lado, esse mito que revela sentidos na e para a história, um amalgama de natureza e história, parece ser a tônica do destino trágico - de culpabilização - da construção também do processo histórico. Nos fragmentos benjaminianos sobre filosofia da história e política lemos, sob a rubrica Ética, o seguinte:

A categoria suprema da história do mundo, que garante a univocidade dos acontecimentos, é a culpa. Cada momento dessa história está marcado pela culpa e implica a culpa. Causa e efeito nunca poderão ser categorias decisivas na estrutura da história do mundo, porque não podem determinar nenhuma totalidade. (...) $\mathrm{A}$ concepção racionalista da História comete o erro de considerar causa ou efeito qualquer totalidade histórica (ou seja, um determinado estado do mundo). Um estado do mundo, no entanto, é apenas, e sempre, culpa (na sua relação com um outro, que virá depois dele). (BENJAMIN, 2013, p. 28)

E esse trecho ganha ainda mais inteligibilidade se lido à luz do fragmento $O$ capitalismo como religião, quando Benjamin indica que

o capitalismo é uma pura religião de culto, talvez a mais extrema que alguma vez existiu. (...) O capitalismo é provavelmente o primeiro caso de um culto que não redime, mas deixa um sentimento de culpa. Uma imensa consciência de culpa, incapaz de redenção, apodera-se desse culto, e, nele, a culpa, em vez de ser redimida, é universalizada, gravada na consciência, até que o próprio Deus é

\footnotetext{
7 BENJAMIN, Walter. As afinidades eletivas de Goethe... p. 34.

8 Cf.: GAGNEBIN, Jeanne Marie. Mito e culpa nos escritos de juventude de Walter Benjamin. In.: GAGNEBIN, Jeanne Marie. Limiar, Aura e Rememoração. Ensaios sobre Walter Benjamin. São Paulo: 34, 2014. p. 57.

Doutor em Literatura pela Universidade Federal de Santa Catarina (UFSC). Atualmente é Professor Adjunto no Departamento de História da Universidade Federal do Paraná (UFPR). Brasileiro, residente em Curitiba-PR. Email: viniciushonesko@gmail.com
} 
apanhado nessa rede de culpa, para que, finalmente, ele próprio se interesse pela sua expiação. (BENJAMIN, p. 35-36)

Para Benjamin, a construção de uma religião cultual só pode ter suas bases fincadas numa compreensão mítica da história, isto é, o processo - o progresso - histórico como uma sucessão de presentes que, enquanto são pura transição, escapam aos viventes e tornam-se, instantânea e constantemente, uma moldura esvaziada no prostíbulo do "era uma vez": moldura que encerra uma imagem de um agora que já é um outrora eternizado como passado e em face do qual nenhuma outra relação resta para o sujeito que para esse quadro olha senão a de culpa. É esse o destino inexorável ao qual nos submetemos quando a natureza se torna (é) um mito e quando este irrompe na história como a possibilidade da verdade.

Benjamin crítica, assim, com uma mesma tacada, tanto as proposições de um historicismo talvez mais ingênuo (que, naquele contexto, poderia encontrar na socialdemocracia sua expressão) quanto a construção de um mito que revelaria uma verdadeira possibilidade de existência, que desvelaria $a$ verdade para o povo alemão, o fascismo. Isto é, tanto os fascistas, que assumem abertamente o mito como uma verdade, quanto os socialdemocratas, que incorrem numa construção mítica do mundo por ilusão, justamente por assumirem a religião capitalista como uma verdade incontornável, ainda que aperfeiçoável no curso do progresso. Nesse sentido, tanto os socialdemocratas quanto os fascistas teriam a mesma relação de submissão ao destino: estes por uma busca da verdade, do mito, revelada na história e que colocaria o destino na posição de desejo de totalidade, aqueles, ao buscarem "os fundamentos que outorgam credibilidade" às explicações que têm aparência de ficções, não percebem que acabam por produzir ficções - pautadas em relações de causas e efeitos, de meios e fins - que outorgam credibilidade a suas explicações do mundo, para retomarmos a questão kantiana. Em outras palavras, o historicismo e a socialdemocracia, com sua crença no progresso e numa emancipação da humanidade que poderia, inclusive, vir por meio da técnica, acabam reféns de uma intuição natural (tal como as estações sismológicas o são em face dos cães) que os lança, irremediavelmente, à submissão e à assunção da culpa como único destino. Na socialdemocracia (e 
em seu modo privilegiado de pensar a história: o historicismo) o mito prevaleceria tendo em sua base, como anota Benjamin nas reflexões preparatórias para as Teses sobre o conceito de história, o "mundo como punição - a punição que primeiro tem de gerar o sujeito a punir" (BARRENTO, 2013, 179). Assim, o capitalismo como religião mostra sua face mítica, cuja imagem, reforça Benjamin, é a do eterno retorno enquanto castigo do aluno que fica retido na escola e que, ao ser projetado à escala cósmica, mostra-se na humanidade que deve copiar seu texto numa infinita repetição (BARRENTO, 2013, 179).

Benjamin ainda caracteriza uma ligação desse mito como base da socialdemocracia à ideia de Direito. A ordem do destino, que comporta a desgraça e a culpa e impossibilita qualquer inocência ao simples fato de viver, é absorvida por esse instrumento de ordem que é o Direito e, assim, relacionando Direito e tragédia, Benjamin, diz que o Direito "erige as leis do destino, da infelicidade e da culpa à condição de medida da pessoa" e faz uma diferenciação fundamental entre o Direito e a Justiça:

Por engano, por ter sido confundida com o reino da justiça, a ordem do direito - que é apenas um resíduo do plano demoníaco na existência humana, na qual os princípios jurídicos não determinam apenas as relações entre os homens, mas também destes com os deuses - manteve-se para além do tempo que inaugurou a vitória sobre os demônios. (BENJAMIN, 2011, p. 93)

Desse modo, o Direito, como modelo de sustentação da sociedade burguesa (e, no fundo, do capitalismo) forjaria um modo da manutenção de resquícios míticos no seio da história, esta que, supostamente, tendo o Direito como instrumento, avançaria como progresso.

É nesse sentido que a $8^{\underline{a}}$ Tese sobre o conceito de história, escrita anos depois, pode ser lida:

A tradição dos oprimidos nos ensina que o "estado de exceção" no qual vivemos é a regra. Precisamos chegar a um conceito de história que dê conta disso. Então surgirá diante de nós nossa tarefa, a de instaurar o real estado de exceção; e graças a isso, nossa posição na luta contra o fascismo tornar-se-á melhor. A chance deste consiste, não por último, em que seus adversários o afrontem em nome do progresso como se este fosse uma norma histórica. - $\mathrm{O}$ espanto em constatar que os acontecimentos que vivemos "ainda" sejam possíveis no século XX não é nenhum espanto filosófico. Ele não está no início de um conhecimento, a menos que seja o de mostrar que a 
representação da história donde provém aquele espanto é insustentável. (BENJAMIN, 2005, p. 83)

No entanto, diante desse diagnóstico de uma mítica que parece ser a tônica de seu tempo - seja ela às claras e que busca uma revelação, seja ela por uma incapacidade de, efetivamente, desvincular-se à submissão ao mito ao se iludir com uma potencialidade emancipadora que julga ter encontrado -, teria Benjamin insinuado alguma possibilidade de rompimento com essa tônica? Em outras palavras, abre Benjamin algum tipo de resposta para a concreção do real estado de exceção?

No ensaio de 1919, Destino e Caráter, a aposta parece vinculada à noção de caráter, o qual, perto do fim do texto, é colocado por Benjamin como algo que persiste no domínio da natureza (e que, portanto, não poderia ser colocado como uma metafísica, por assim dizer) mas que não entretém laços com a tragédia, mas com a comédia, e que possibilitaria uma inversão nos humanos da suposta culpa natural em uma inocência natural (algo que, no âmbito do cristianismo, poderíamos dizer ser próximo ao pelagianismo ${ }^{9}$ ). 0 caráter, assim, abre aos humanos uma possibilidade libertadora, emancipatória, que, todavia, não é vinculada a uma racionalidade que pretende suturar os mitos - o destino - com a busca de fundamentos credíveis que, no fundo, apenas recobrem o problema da existência natural com a projeção de uma razão dominadora que, por fim, como já vimos, patina e volta àquilo mesmo que pretendia suturar (o destino, o mito). Pelo contrário, o caráter carrega sempre uma componente de violência que é destruidora, e, nesse sentido, não se submete às relações de causalidade ou de finalidade, mas, assumindo-se como uma totalidade histórica (uma mônada), pode suspender a regra do estado de exceção no qual vivemos.

9 Cf.: AGAMBEN, Giorgio. Desapropriada maneira. In.: AGAMBEN, Giorgio. Categorias Italianas. Estudos de poética e literatura. Florianópolis: Edufsc, 2014. Trad.: Carlos E. S. Capela e Vinícius N. Honesko. p. 117. Há uma importante leitura de Agamben, em moldes absolutamente benjaminianos, a respeito de uma possibilidade de desvinculação do destino trágico por meio de uma emancipação cômica. Trata-se do ensaio Pulcinella. Ovvero divertimenti per li regazzi, no qual o filósofo analisa a famosa figura da comédia a arte a partir das pinturas de Giandomenico e Gianbattista Tiepolo e pensa uma inocência natural capaz de romper com o laço trágico que atravessa a história (e a política) no Ocidente e dar abertura ao que Agamben chama de forma-de-vida. Cf.: AGAMBEN, Giorgio. Pulcinella. Ovvero divertimenti per li regazzi. Roma: Nottetempo, 2015.

Doutor em Literatura pela Universidade Federal de Santa Catarina (UFSC). Atualmente é Professor Adjunto no Departamento de História da Universidade Federal do Paraná (UFPR). Brasileiro, residente em Curitiba-PR. Email: viniciushonesko@gmail.com 
A dimensão de uma violência que suspende a relação entre meios e fins é a pedra de toque do ensaio Para uma crítica da violência, publicado em 1921. Nele, Benjamin reflete sobre uma irrupção política que possa liberar a política de uma estruturação que se dê por meio da instituição de meios e fins. É preciso lembrar que quando da eclosão e do fim de revolta espartaquista, que provavelmente influencia a escrita desse ensaio, algo como, respectivamente, uma suspensão de uma ordem temporal (o Reich) é seguido por uma reordenação (que põe fim ao Reich e instaura a República) mas que, no fundo, é apaziguado numa reabsorção na ordem mítica, a ordem burguesa, justamente por meio de uma constituição do Estado. A reordenação da vida em comum e da ordem temporal por meio do Direito reforça a ideia de que este viria como apanágio do mítico como único fundamento possível para a política e, via de consequência, para o processo histórico. Nesse sentido, a violência rompante, enquanto propõe meios para determinados fins, sempre é absorvida ora como violência que conserva o direito (tanto a que até então existia na ordem do Reich e que passará a existir, após o fim da revolta, na ordem da República) ora como violência que põe o direito (aquela que, durante 0 momento de suspensão do tempo que é a revolta, a esta põe fim instaurando uma nova ordem em que o Direito, eivado do mito, afirma-se como destino político). Assim é que, anos depois, já diante do fascismo (no qual o mito não se esconde sob o Direito mas é o próprio direito: a palavra do Führer é a lei), nas teses, é que será possível a Benjamin dizer que "o estado de exceção em que vivemos é a regra". Ora, o real estado de exceção só poderia vir com uma suspensão efetiva, isto é, com a irrupção de uma violência que não mais se deixa apreender pela lógica dos meios e dos fins, ou seja, uma violência pura ou divina (BENJAMIN, 2011), que é atestada pela "ausência de qualquer instauração de direito. Nesse sentido, também é justificado designar essa violência também como aniquiladora" (BENJAMIN, 2011, 152).

A partir dessa imagem da aniquilação é que podemos pensar aquele método da política universal, o niilismo, que fecha o enigmático Fragmento teológico-político (BENJAMIN, 2013). À medida em que a violência se subtrai ao mito, ao destino infeliz, para ingressar na esfera do eternamente transitório, 
da eternidade de uma dissolução (a suspensão que é a revolta e que permanece nessa transitoriedade, permanece um puro meio), é que a medida do político e, consequentemente da história, se faz pela emancipação na história, pela vida liberada do destino e aberta à felicidade. Aniquilação, dissolução, destruição: suplantar o mito e o destino, enquanto tarefa do caráter, implica essa violência que já não entretece relações com a tragédia (com o Direito), mas que, suspendendo tais relações, abre o campo da comédia e da Justiça. É nesse ponto que a imagem do caráter destrutivo, presente em Imagens do Pensamento, ganha um brilho especial na escrita benjaminiana, e a dimensão do jogo de submissão e liberação da natureza se dá no ritmo em que o caráter destrutivo se lança à vida: "o caráter destrutivo está sempre trabalhando de ânimo novo. É a natureza que lhe prescreve o ritmo, ao menos indiretamente; pois ele deve se antecipar a ela, senão é ela mesma que vai se encarregar da destruição" (BENJAMIN, 1995, 236). Ao persistir na natureza dado que a ela seria impossível se subtrair - o encontro com a possibilidade de desvencilhar-se da destruição impingida pelo destino está na antecipação à própria natureza. Como meio de livrar-se da culpa, a destruição deve se colocar sempre de antemão à marcha natural, à revelação da verdade mítica na história. Nesse sentido, continua Benjamin

\footnotetext{
O caráter destrutivo tem a consciência do homem histórico, cujo sentimento básico é uma desconfiança insuperável na marcha das coisas e a disposição com que, a todo momento, toma conhecimento de que tudo pode andar mal. Por isso, o caráter destrutivo é a confiança em pessoa.

O caráter destrutivo não vê nada de duradouro. Mas eis precisamente por que vê caminhos por toda parte. Onde outros esbarram em muros ou montanhas, também aí ele vê um caminho. Já que o vê por toda parte, tem de desobstruí-lo também por toda parte. Nem sempre com brutalidade, às vezes com refinamento. Já que vê caminhos por toda parte, está sempre na encruzilhada. Nenhum momento é capaz de saber o que o próximo traz. O que existe ele converte em ruínas, não por causa das ruinas, mas por causa do caminho que passa através delas. (BENJAMIN, 1995, p. 236-237)
}

Mas como seria possível, diante do destino, diante de uma violência que coloca e de uma violência que mantém o Direito, a ativação do caráter, a forja de uma violência pura que já não propõe uma instituição, mas apenas a destruição e a destituição? Em que sentido pode haver uma possibilidade de 
destituição da culpa e essa abertura para a destruição que o caráter pode efetivar?

Gostaria de, por fim, retomar um leitor de Benjamin que nos traz possibilidades interessantes a esse respeito e, também, para nossas questões políticas mais urgentes: Furio Jesi.

Em 1968, diante dos acontecimentos de maio, Jesi escreve Spartakus. Simbologia da revolta, texto que só será publicado postumamente (dado que Jesi morre em 1980) em 2000. No texto, Jesi reflete sobre o problema do mito e seus enlaces em relação à questão da revolta espartaquista de 1918. Tendo uma compreensão de mito próxima àquela de Benjamin, ${ }^{10}$ Jesi, todavia, discute diretamente com seu mestre: o mitólogo Karl Kerényi (e 1968 também será o ano de rompimento de relações). Para este, mais próximo de Jung e Klages, o mito poderia ser compreendido de dois modos distintos: mito genuíno, "que surge espontaneamente das profundezas da psique, determina com sua presença no nível da consciência uma realidade linguística cujo caráter coletivo corresponde ao valor coletivo" (JESI, 2002, 35-36) e mito tecnicizado, que seria evocado intencionalmente pelos homens para a obtenção de certos fins, sobretudo políticos. A proposta de um conservador como Kerényi visa,

10 Cf.: JESI, Furio. Mito. Milano: Arnoldo Mondadori, 1980. p. 12. "O moderno estudo do mito encontra um primeiro obstáculo na dificuldade de circunscrever com suficiente rigor seu âmbito e seu objeto. A palavra "mito" possui hoje múltiplos significados. Dedicar-se ao estudo do mito pressupõe que um ou mais de um de todos esses significados, separadamente ou em conjunto, estejam em relação com uma verdade objetiva: mesmo que essa relação seja de negação. Essa verdade objetiva pode ser o puro valor auto-significante da palavra "mito". Nesse caso, haveria duas alternativas: a palavra "mito", em um ou mais de um ou em todos os seus significados, separadamente ou em conjunto, poderia ser: 1) um puro símbolo que repousa em si mesmo, que remete unicamente a si mesmo e encontra em si a própria origem e a própria realização; 2) um puro flatus vocis, que não remete a nada, nem mesmo a si mesmo, uma vez que o si mesmo ao qual remete é verdade enquanto não é. A verdade objetiva com a qual a palavra "mito" pode estar em relação, todavia, também pode ser um objeto que goze de existência autônoma em face da palavra "mito". Nesse caso, o estudo "do mito" não poderia se limitar a ser estudo da palavra "mito" em seus múltiplos significados, mas deveria ser também estudo do objeto existente de modo autônomo em relação a essa palavra e, ainda assim, em relação com esta: objeto que seria $o$ mito. A discriminação entre essas possibilidades deveria ser preliminar ao estudo do mito, a fim de que este agisse em um âmbito e sobre um objeto rigorosamente circunscritos. Mas, como observamos desde o princípio, o pesquisador moderno se encontra na impossibilidade de realizar tais discriminações preliminares e deve procurar proceder face a estas no próprio curso de seu estudo, operando em âmbitos e sobre objetos escolhidos empiricamente: daí o risco evidente de iludir-se, imaginando ter atingido a discriminação de maneira rigorosa, quando, de fato, ela foi realizada em âmbitos e sobre objetos extrínsecos ao problema ou inadequados a uma configuração suficientemente ampla do problema."

Doutor em Literatura pela Universidade Federal de Santa Catarina (UFSC). Atualmente é Professor Adjunto no Departamento de História da Universidade Federal do Paraná (UFPR). Brasileiro, residente em Curitiba-PR. Email: viniciushonesko@gmail.com 
justamente, à crítica do modelo fascista de mito, um mito tecnicizado por excelência. Para Kerényi, o acesso ao mito genuíno seria muito próximo à revelação, tal como a proposta por Pareyson (e não é à toa que os modelos de análise do mitólogo são justamente tanto as festas ${ }^{11}$ no âmbito da etnologia, quanto, por exemplo, as festas da República durante os anos pósrevolucionários na França), enquanto o mito tecnicizado seria uma instrumentalização política, uma forja propagandística de um suposto e, assim, falso mito genuíno (e a imagem das grandes multidões nos discursos de Hitler ou Mussolini podem ser o exemplo)

Em Spartakus, Jesi radicaliza essa oposição de Kerényi ao dizer que toda experiência do mito é sempre uma tenicização. Para nós, modernos, não haveria possibilidade de experiência autêntica, genuína, do mito e, revertendo os termos de Kerényi, Jesi fala que aquilo a que temos acesso é uma propaganda genuína, operando uma arriscada associação que para Kerényi seria impossível. Assim nos lembra Andrea Cavalletti a respeito desse jogo de inversão que Jesi faz de Kerényi:

Onde há propaganda e política, sustentava Kerényi, não pode haver genuinidade do mito. Onde o mito é genuíno, sustenta ao contrário Jesi, não há mestres inspirados e solitários, mas apenas uma verdadeira coletividade, que se liberta subvertendo as fronteiras da sociedade atual. No gesto do monge vietnamita [referência ao monge que põe fogo no próprio corpo no Vietnã, em 1963], como nos gestos de quem colocava em jogo a própria vida nas filas dos espartaquistas em Berlim, cumpre-se assim para ele o que para Kerényi jamais poderia se cumprir, isto é, a perfeita "sutura entre o mito genuíno, aflorado espontânea e desinteressadamente das profundezas da

\footnotetext{
${ }^{11}$ Quanto à dimensão da festa é crucial lembrar das análises de Rousseau feitas por Jacques Derrida. Segundo o filósofo argelino, o problema da festa estaria em Rousseau no polo da origem simples da sociedade nascente. Cf.: DERRIDA, Jacques. Gramatologia. São Paulo: Perspectiva, 2008. Trad.: Miriam Chnaiderman e Renato Jeanine Ribeiro. pp. 318-320. "Assim a língua e a sociedade originais, tais como apareceram nas regiões quentes, são absolutamente puras. (...) [a língua] Já não é animal, pois exprime paixão, mas não é totalmente convencional, pois se esquiva da articulação. A origem desta sociedade não é um contrato, não passa por tratados, convenções, leis, diplomatas e representantes. É uma festa. Ela se consome na presença. (...) A festa segundo Rousseau exclui o jogo. O momento da festa é o momento desta continuidade pura, da in-diferência entre o tempo do desejo e o tempo do prazer. Antes da festa, não há, no estado de pura natureza, experiência do contínuo; depois da festa, começa a experiência do descontínuo; a festa é o modelo da experiência contínua. Por isso, tudo o que podemos fixar em oposições de conceitos se refere à sociedade formada no dia seguinte à festa."
}

Doutor em Literatura pela Universidade Federal de Santa Catarina (UFSC). Atualmente é Professor Adjunto no Departamento de História da Universidade Federal do Paraná (UFPR). Brasileiro, residente em Curitiba-PR. Email: viniciushonesko@gmail.com 
psique, e a autêntica propaganda política". (CAVALLETTI, 2018, no prelo)

Essa impossibilidade de uma genuinidade de qualquer mito saltaria no momento revoltoso, isto é, no momento de suspensão do tempo histórico, quando o sujeito individual se dissolveria numa coletividade que violentamente coloca em xeque o mito fundamental da sociedade burguesa (o mito do Direito, da violência que mantém o Direito). Todavia, Jesi alerta que no gesto político do revoltoso - cujo outro nome pode ser a propaganda genuína - também haveria uma dimensão mítica, isto é, não haveria, de modo aparentemente paradoxal, escapatória a um mito que parece anteceder qualquer possibilidade de sua destruição (algo que também podemos ler em Benjamin, quando, de outro modo, reconhece que o caráter ainda persiste no domínio da natureza mas que a ela deve adiantar-se). Ora, assim como para Benjamin não nos é possível e escapar à natureza (a certa dimensão do mito, portanto), na leitura de Jesi, também não é possível, mesmo numa revolta, o apagamento do mito, mas apenas a destruição do modo propagandístico do inimigo que opera sobre o mito, neste caso, o mito burguês do Direito e da história como um continuum que tende ao progresso. Em Jesi, portanto, tal como a violência pura em Benjamin, a dinâmica da revolta é uma possibilidade de destruição do mito burguês que, usando de uma propaganda genuína, pode nos dar acesso à história:

O eu que padece o tempo histórico mesmo sendo partícipe do tempo mítico, no instante em que acede ao mito "se expande como uma fonte", isto é, destrói a si mesmo em um processo dinâmico que envolve sua duração histórica. Em suma, o eu é verdadeiramente partícipe do fluxo da história quando com este chega a identificar o decurso de sua destruição, e, assim, de seu acesso ao mito. (JESI, 2002, no prelo)

Pode parecer que essa dimensão do mito que persiste tenha, por si só, uma dimensão mitológica, isto é, que haveria, por parte de Jesi (e também de Benjamin), uma assunção do mito como origem. Todavia, essa origem mítica não é uma revelação de uma verdade fundamental para a forja de uma ordem histórica e política. O originário é aqui, nos termos de Benjamin (2016), aquilo que não tem nada a ver com uma gênese, com uma fonte de verdade ontológica, mas que se reconhece como restauração e reconstituição e, 
também, como incompletude e inacabamento. É nesse sentido que Jesi vai, alguns anos depois das análises de Spartakus, criar a noção máquina mitológica, um modelo gnosiológico por meio do qual, dado que o mito genuíno é impossível, os mitólogos poderiam analisar os modos de concreção do mito na história. A máquina seria uma espécie de caixa cujas paredes seriam compostas de matérias mitológicos - narrativas sobre o mito - que discorreriam sobre suposto mito que estaria no interior da caixa. Essas paredes, todavia, seriam impenetráveis dado que o contato direto com o mito (o que os etnólogos supostamente veriam nas festas dos indígenas - que Jesi chama de diferentes) é impossível (JESI, 1014). Nesse sentido, a astúcia da máquina estaria no fato de ela nos fazer crer que em seu centro haveria um motor imóvel que, justamente por não ser crível, nos obrigaria a crer na máquina. Em certo sentido, a dimensão do mito que irrompe na história sem que os agentes históricos dela se dessem conta, sobre a qual nos fala Benjamin, mostra-se, nessa armação teórica de Jesi (2013), de modo exemplar. A máquina produz materiais mitológicos, isto é, narrativas sobre o mito, mito este que ela, a máquina, nos faz supor ser inexistente. Melhor dizendo, colocados num lugar inacessível, os mitos seriam apenas o vazio, o não-ser - o núcleo da realidade que outrora era alcançado pela epifania festiva -, a partir do qual a máquina entra em funcionamento e sustenta o suposto interdito que é a origem. Ainda assim, "a máquina mitológica, por sua própria natureza" - nos diz Jesi em A festa e a máquina mitológica -, "é o que indica algo que não pode ser visto; quem usufrui de seu funcionamento se encontra vendo os traços de uma visão - o funcionamento da máquina -, não a visão em si - o mito" (JESI, 2014, 55). Em suma, para nós, modernos, a máquina se coloca no lugar que para os antigos e para os indígenas supostamente estaria o mito genuíno; no entanto, essa assertiva só por nós, modernos, pode ser proferida, ou seja, não há garantias de que os antigos tivessem alguma verdadeira visão, não há nenhum modo de aferir a existência do mito genuíno.

Em 1972, ao retomar os materiais de Spartakus - que, lembremos, não haviam sido publicados -, Jesi elabora uma primeira versão de sua máquina mitológica no ensaio a Leitura do Bateau ivre de Rimbaud, no qual o problema 
do mito é colocado em sua relação temporal com a história. Nessa primeira imagem da máquina, Jesi, por meio de um sutil jogo linguístico, faz do movimento gnosiológico um ato de fé:

Crer que o mito esteja autonomamente dentro da máquina mitológica (...) só pode querer dizer que o mito não existe (non c'è) - que a essência do lugar comum não existe (non è). Se existem (ci sono), estão num "outro mundo": não estão aqui (ci non-sono). ("J'écrivais des silences... je notais l'inexprimable. Je fixais des vertiges"). Mesmo o mais convicto defensor da não-fé é obrigado a consentir num involuntário ato de fé: não há fé mais exata num "outro mundo" que não existe aqui (ci non-è) ${ }^{12}$ do que a declaração de que tal "outro mundo" não existe (non è). A partícula "ci" adere estreitamente ao "j'aimais" de Rimbaud e indica apenas a adesão deliberada por oposição à adesão involuntária. (JESI, 2015, p. 74)

A partir dessa verificação de uma crença por negação no conteúdo da máquina, Jesi expõe os limites do problema do conhecimento que estão intimamente imbricados na dimensão política. Nesse sentido, aquilo que valia para a questão da interdição da festa, do encontro epifânico com o mito (um mito revelado na história, por assim dizer), desenvolve-se agora na compreensão da revolta que, equiparada à festa, teria seu antagonismo na revolução. Enquanto revolta seria a suspensão do tempo histórico (justamente, tal como a festa) a revolução seria uma espécie de mudança certa no tempo histórico. Essa distinção, por longo tempo exposta em Spartakus, reaparece e, agora, é exibida em seu caráter inextrincável para a gnosiologia e para a política. Em outras palavras, na Leitura, a revolta, como expressão do bateau ivre na dimensão da suspensão do tempo histórico e abertura para um tempo do eterno presente, e a revolução, como perspectiva de certa mudança no tempo histórico, ainda são modos de manejo da máquina:

\footnotetext{
12 N.T.: Jesi, nesse parágrafo, elabora, por meio de um sutil jogo linguístico, um dos pontos fundamentais de seu conceito de "máquina mitológica". O verbo "esserci" é usado com o sentido de "haver, existir". A expressão "ci non-è" - não usual, assim como a anterior "ci nonsono" - carrega, porém, uma polissignificação quase intraduzível. A tradução que mantemos no texto - "não existe aqui" - não dá conta do fato de que a partícula "ci" pode também fazer referência a um "para nós" (e em relação ao uso da partícula a que o próprio Jesi fará menção nos argumentos que seguem). Ou seja, outra tradução possível seria "não existe para nós". Além disso, outra questão implícita na expressão é o problema ôntico/ontológico, ao qual Jesi também está aqui se referindo de modo indireto. Assim, a expressão também poderia ser traduzida por "não é aqui" ou, ainda, "não é para nós". Optamos, portanto, por manter as expressões do original italiano entre parênteses (inclusive nas outras variações do verbo "esserci" que aparecem a partir daqui).
}

Doutor em Literatura pela Universidade Federal de Santa Catarina (UFSC). Atualmente é Professor Adjunto no Departamento de História da Universidade Federal do Paraná (UFPR). Brasileiro, residente em Curitiba-PR. Email: viniciushonesko@gmail.com 
a revolta e a revolução, não contradizem em nível conceitual o modelo proposto pela máquina mitológica. Pelo contrário: na perspectiva aberta, seja por uma, seja por outra, esse modelo acaba por se identificar com o a priori que permanece como fundamento sólido e obscuro do processo gnosiológico. Frente à essência (...) do mito não há autêntica alternativa conceitual, mas apenas alternativa gestual, de comportamento, só que de comportamento que permanece circunscrito dentro da caixa delimitada pelas paredes da máquina mitológica. Revolta e revolução, em nível conceitual, permanecem apenas diferentes articulações (suspensão do tempo; tempo "certo") do tempo que vige no interior daquela caixa. O "bateau ivre" não quebrou aquele tempo: tão somente gozou da sua suspensão, limitada, e sobretudo não provocada pelo "bateau" mas advinda como uma epifania de modo que ele gozasse dela: "Je ne me sentis plus...". E nem mesmo se, em vez de uma revolta, tivesse ocorrido uma revolução (se o "bateau", depois de ter calculado o momento mais apropriado, o momento "certo", tivesse se desembaraçado dos marinheiros: Potëmkin ameaçador e intolerante não apenas para com os oficiais, mas para com todos os homens), o tempo teria sido quebrado: teria sido privilegiado, declarado "certo", mas não quebrado, já que diante da raiz do tempo, do vazio de ser que se encontra no interior da máquina mitológica e ao qual a máquina mitológica remete, a revolução teria declarado um "não existe" (non è) perfeitamente coincidente com 0 argumento ontológico. (JESI, 2014, p. 74)

Nessa dinâmica, ao final da revolta ou da revolução, a máquina mitológica, tal como uma cabeça de hidra, tornaria a refazer-se e a velar em seu centro aquilo que, por meio da revolta, os revoltosos tentaram ver e que, por meio da revolução, os revolucionários negaram a existência. De um modo ou de outro, a máquina prevalece e um originário - aquilo que seria capaz de, ou visto ou tendo sua inexistência confirmada, possibilitar um novo modo de conhecer e fazer política - continua inacessível e recoberto pelos materiais mitológicos produzidos pela máquina. Mas, nessa impossibilidade anunciada, não haveria um modo de destruir a máquina?

Na prospecção teórica de Jesi, portanto, revolta e revolução não seriam alternativas suficientes, do ponto de vista conceitual, para a destruição da máquina, haja vista que, na primeira, certa crença em um conteúdo escondido na máquina seria o motivo do movimento insurgente (algo como uma verdade epifânica capaz de dar vazão à destruição do que seria seu mito antagônico, o continuum do cotidiano) ao passo que, na segunda, as táticas e estratégias para mudanças no tempo, ao negar um conteúdo escondido, aceitariam, por negação, esse mesmo conteúdo como não sendo/existindo para nós. No 
entanto, ainda em Spartakus uma tentativa de destruição das mitologias parece desenhada. É o que nos lembra Andrea Cavalletti:

A experiência crucial de Spartakus consistia assim em tentar subtrairse às mitologias que exercem seu encantamento sobre os revoltosos de ontem e de hoje, em pensar uma linha de fuga do círculo vicioso dos "grandes sacrificadores" e das "grandes vítimas", ou melhor, da oposição funcional que separa o tempo imóvel ou o eterno presente do mito do transcorrer da história. Para isso, Jesi propunha uma surpreendente filosofia da subjetividade, uma teoria da "dupla Sofia", ou seja, da consciência como denominador comum entre os mundos da história e do mito. O eu salvo pelo sacrifício não é aquele glorificado nas imagens do herói (de Rosa Luxemburgo e Karl Liebknecht, em certas cenografias expressionistas), como obviamente não é aquele que sobre por acaso sobrevive ou se subtrai à batalha para voltar aos estatutos da sociedade burguesa. $O$ eu que se salva é para Jesi aquele que foge do jogo que colabora à oposição mito/história, situando-se exatamente no lugar de seu cruzamento e que "conhece ao mesmo tempo (...) a permanência e a destruição de si, o tempo histórico e o tempo do mito". (CAVALLETTI, 2013, p. 14-15)

Mesmo que em Spartakus o modelo da máquina estivesse ausente e prevalecesse a ideia de um eu, um sujeito, que deve ser destruído no momento da revolta, ${ }^{13}$ é essa mesma destruição que Jesi prevê para a máquina e que abrirá uma nova possibilidade gnosiológica e política, para além das mitologias e que não seria apenas um sonho com o encontro epifânico com um mito originário (revolta) ou com um nada originário (revolução). No entanto, essa destruição, posto que não pode ser via simples revolução ou revolta, não estaria apenas num plano de atuação na máquina, mas nas condições que possibilitam a produção da máquina.

Em outras palavras, ao propor a máquina, Jesi apontaria para um complexo modo de conhecer que, respondendo às urgências demandadas pela palavra mito, em grande medida deixaria para trás os modelos que propunham uma possibilidade analítica da festa (e do mito) dos indígenas ou dos antigos

\footnotetext{
13 JESI, Furio. Spartakus. Simbologia da revolta... no prelo. " O eu, portanto, no instante em que é consciente de si é também materializado de morte, e seu abismar-se na morte se realiza de modo perene durante essa que temos o hábito de considerar a vida do homem. $\mathrm{O}$ eu, portanto, conhece ao mesmo tempo a vida e a morte, a permanência e a destruição de si, o tempo histórico e o tempo do mito. Ele é o elemento comum, o ponto de intersecção entre dois universos: o da vida e o do tempo histórico, o da morte e o do tempo mítico. Esse ponto de contato adquire realidade paradoxal quando se considera que o tempo histórico está em movimento perene, enquanto o tempo mítico é perene imobilidade."
}

Doutor em Literatura pela Universidade Federal de Santa Catarina (UFSC). Atualmente é Professor Adjunto no Departamento de História da Universidade Federal do Paraná (UFPR). Brasileiro, residente em Curitiba-PR. Email: viniciushonesko@gmail.com 
enquanto forma de análise de um objeto, e que, além disso, trataria de pensar a posição do cientista nesse jogo de conhecimento: em suma, a máquina mostraria que aquele que pretende conhecer sempre está implicado em seu objeto. Todavia, Jesi também se dá conta de que o modelo da máquina esbarra no limite que é certo caráter mitológico que lhe é ínsito, algo para o qual em um texto paradigmático, chamado Gastronomia Mitológica, ele aponta. Aí, Jesi torce o mecanismo da máquina sobre si mesmo e reforça que essa nuança mitológica que permanece na máquina encontra sua possibilidade de destruição numa dimensão política. É também o que vai reafirmar no último de seus textos sobre a máquina mitológica: Cognoscibilidade da festa, de 1976:

\begin{abstract}
A possibilidade dessa destruição é exclusivamente política; seu risco, do ponto de vista gnosiológico, é que as máquinas sejam verdadeiramente vazias e que, portanto, demonstrada por fim sua vacuidade, ela mesma se imponha como uma paradoxal máquina negativa que produz o nada a partir do nada. Não se trata, todavia, de um verdadeiro risco, a partir do momento em que nos é impossível por ora, antes da destruição, avançar qualquer hipótese confiável em relação ao depois (a própria expressão "máquina negativa que produz o nada a partir do nada" está ligada ao hoje, é o previsível hoje, assim, o mais improvável amanhã). Destruir a situação que torna verdadeira e produtiva as máquinas (...) significa, além disso, ir para além dos limites da cultura burguesa, não só tentar deformar-lhe um pouco suas barreiras de confins. (JESI, 2013, p. 107)
\end{abstract}

A destruição da situação que torna a máquina produtiva só pode ter início afrontando a máquina mitológica como modelo e objeto de conhecimento ao mesmo tempo, isto é, anunciando ao mesmo tempo a existência e a nãoexistência daquilo que a máquina diz conter (CAVALLETTI, 2005). A destruição, portanto, seria um modo de ir mais além dos fascínios do mito da morte heroica dos revoltosos e também das batalhas dos revolucionários pela vitória numa luta que, no fundo, seria apenas por apoderar-se do mito do inimigo, qual seja, o continuum da história da sociedade capitalista (numa manutenção da máquina que, assim, apenas giraria em outro sentido). Destruição em Jesi, portanto, tal como em seu mestre Benjamin, está em não ver nada de duradouro justamente por ver caminhos por todas as partes, em estar sempre numa encruzilhada, tendo em vista que nenhum momento é capaz de saber o que o próximo traz (BENJAMIN, 1995), ou ainda, está em desativar - destituir - a máquina de seu posto de produção de cisões (tempo 
histórico/ tempo mítico, humano/não humano etc.) por meio das quais, politicamente, faz-se a manutenção de materiais mitológicos que, por sua vez, sustentam a produção da máquina ad aeternum num continuum histórico cujos dominadores são sempre conhecidos. O tempo da destruição é sempre agora, é a "época dos tenazes" (COMITÊ INVISÍVEL, 2017, 20), é quando tempo do mito e tempo da história já não fazem sentidos separados porque a destruição remoça e nos abre à felicidade de saber que combatemos a batalha e esta, enquanto dura, é uma espécie de vitória.

\section{REFERÊNCIAS}

ADORNO, Theodor; SCHOLEM, Gershom (org.). The correspondence of

Walter Benjamin. 1910-1940. Chicago: The University of Chicago Press, 1994. Translated by Manfred R. Jacobson and Evelyn M. Jacobson.

AGAMBEN, Giorgio. Desapropriada maneira. In_ : AGAMBEN, Giorgio.

Categorias Italianas. Estudos de poética e literatura. Florianópolis: Edufsc, 2014. Trad.: Carlos E. S. Capela e Vinícius N. Honesko.

Nottetempo, 2015.

Pulcinella. Ovvero divertimenti per li regazzi. Roma:

BARRENTO, João. Comentários. In_: BENJAMIN, Walter. 0 anjo da história. Belo Horizonte: Autêntica, 2013. Trad.: João Barrento.

BENJAMIN, Walter. As afinidades eletivas de Goethe. In _ : BENJAMIN, Walter. Ensaios reunidos: escritos sobre Goethe. São Paulo: 34/Duas Cidades, 2009. Trad.: Mônica Krauz Bornebusch, Irene Aron e Sidney Camargo.

Destino e Caráter. In : BENJAMIN, Walter. Escritos sobre Mito e Linguagem. São Paulo: 34/Duas Cidades, 2011. Org.: Jeanne Marie Gagnebin. Trad.: Ernani Chaves.

. Eduard Fuchs, colecionador e historiador. In _ : BENJAMIN,

Walter. O Anjo da História. Belo Horizonte: Autêntica, 2013. Trad.: João

Barrento.

. Fragmentos (filosofia da História e política). In

BENJAMIN, Walter. O anjo da história. Belo Horizonte: Autêntica, 2013. Trad.: João Barrento.

Doutor em Literatura pela Universidade Federal de Santa Catarina (UFSC). Atualmente é Professor Adjunto no Departamento de História da Universidade Federal do Paraná (UFPR). Brasileiro, residente em Curitiba-PR. Email: viniciushonesko@gmail.com 
. Fragmento Teológico-Político. In_: BENJAMIN, Walter. 0 anjo da história. Belo Horizonte: Autêntica, 2013. Trad.: João Barrento.

BENJAMIN, Walter. Imagens do Pensamento. In_ : BENJAMIN, Walter. Obras Escolhidas. II Rua de Mão Única. São Paulo: Brasiliense, 1995. Trad.: Rubens Rodrigues Torres Filho, José Carlos Martins Barbosa.

O capitalismo como religião. In_: BENJAMIN, Walter. $\mathbf{O}$ anjo da história. Belo Horizonte: Autêntica, 2013. Trad.: João Barrento.

O Terramoto de Lisboa. In _ : Gratuita: volume 2. Belo Horizonte: Chão da Feira, 2015. Org. Maria Carolina Fenati. Trad.: João Barrento.

. Origem do drama trágico alemão. Belo Horizonte:

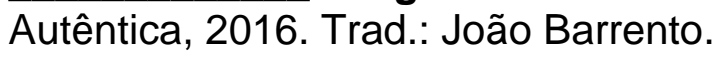

. Para uma crítica da violência. In_ _ BENJAMIN, Walter. Escritos sobre Mito e Linguagem. São Paulo: 34/Duas Cidades, 2011. Org.: Jeanne Marie Gagnebin. Trad.: Ernani Chaves.

Teses sobre o conceito de história. In_: LÖWY, Michel. Walter Benjamin: aviso de incêndio. Uma leitura das teses "Sobre o conceito de história". São Paulo: Boitempo, 2005. Trad. das Teses: Jeanne Marie Gagnebin e Marcus Lutz Müller.

CAVALLETTI, Andrea. Conoscibilità di Bachofen. In_: JESI, Furio. Bachofen. Torino: Bollati Boringhieri, 2005. A cura di Andrea Cavalletti.

. Festa, scrittura e distruzione. In.: JESI, Furio. Il tempo della festa. Roma: Nottetempo, 2013. A cura di Andrea Cavalletti.

. Ler Spartakus. In _ : JESI, Furio. Spartakus. Simbologia da revolta. São Paulo: N-1, 2018. Trad.: Vinícius Honesko.

CHITUSSI, Barbara. Aura e imagem onírica em Walter Benjamin. Texto inédito cuja tradução, de Vinícius Honesko, está no prelo pela editora UFMG, em livro organizado por Márcio Seligmann-Silva e Georg Otte.

COMITÊ INVISÍVEL. Motim e Destituição. Agora. São Paulo: N-1, 2017. Trad.: Vinícius Honesko.

DERRIDA, Jacques. Gramatologia. São Paulo: Perspectiva, 2008. Trad.: Miriam Chnaiderman e Renato Jeanine Ribeiro.

GAGNEBIN, Jeanne Marie. Apresentação. In_: BENJAMIN, Walter. Escritos sobre Mito e Linguagem. São Paulo: 34/Duas Cidades, 2011. Org.: Jeanne Marie Gagnebin. Trad.: Susana Kampf Lages e Ernani Chaves. 
. Mito e culpa nos escritos de juventude de Walter Benjamin. In__: GAGNEBIN, Jeanne Marie. Limiar, Aura e Rememoração. Ensaios sobre Walter Benjamin. São Paulo: 34, 2014.

HERNANDES MARCOS, Maximiliano. Un texto de Immanuel Kant sobre las causas de los terremotos (1756) In__: Cuadernos Dieciochistas. Vol. 6 (2005) Universidad de Salamanca.

JESI, Furio. A festa e a máquina mitológica. In_ : Boletim do Nelic. v. 14, n. 22. (2014) Florianópolis: UFSC. Trad.: Vinícius N. Honesko.

. Cognoscibilità della festa. In_: JESI, Furio. II tempo della festa. Roma: Nottetempo, 2013. A cura di Andrea Cavalletti.

. Leitura do Bateau ivre de Rimbaud. In.: Outra Travessia. n. 19. A Arte, entre a festa e a mudez. UFSC. $1^{\circ}$ Semestre de 2015. Trad.: Fernando Scheibe e Vinícius N. Honesko. . Mito. Milano: Arnoldo Mondadori, 1980.

Mito e linguaggio della collettività. In.: JESI, Furio. Letteratura e mito.

Milano: Einaudi, 2002.

PAREYSON, Luigi. Ontologia da liberdade. O mal e o sofrimento. São Paulo: Loyola/ Instituto Italiano de Cultura de São Paulo, 2017. Trad.: Vinícius Honesko. 